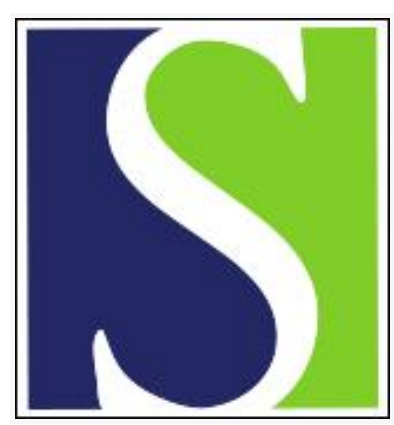

Scand J Work Environ Health 1994;20(3):184-188

https://doi.org/10.5271/sjweh.1410

Issue date: 01 Jun 1994

Etiologic fractions for physical work load, sports and overweight in the occurrence of coxarthrosis.

by Olsen $\mathrm{O}$, Vingard E, Koster M, Alfredsson $\mathrm{L}$

Affiliation: Department of Occupational Medicine, National Institute of Occupational Health, Denmark.

This article in PubMed: www.ncbi.nlm.nih.gov/pubmed/7973490

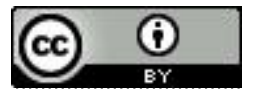




\title{
Etiologic fractions for physical work load, sports and overweight in the occurrence of coxarthrosis
}

\author{
by Ole Olsen, MSc, ${ }^{1}$ Eva Vingård, MD, ${ }^{2}$ Max Köster, BA, ${ }^{2}$ Lars Alfredsson, $\mathrm{PhD}^{2,3}$
}

\begin{abstract}
OLSEN O, VINGÅRD E, KÖSTER M, ALFREDSSON L. Etiologic fractions for physical work load, sports and overweight in the occurrence of coxarthrosis. Scand J Work Environ Health 1994;20: $184-8$.
\end{abstract}

\begin{abstract}
OBJEctives - The aim of this study was to estimate the impact of physical work load, sports, and overweight on the incidence of coxarthrosis.

Methons - A case-referent study was made of 239 male recipients of a hip prosthesis and 302 men randomly selected from the general population. Information was obtained by means of an interview and questionnaire. Exposures to physical work load and sports were measured as the cumulative number of hours of exposure up to 49 years of age. Overweight was measured as the estimated body mass index at 30 or 40 years of age.

REsults - The etiologic fraction related to the three risk factors was $40 \%$ for physical work load, $55 \%$ for sports, and $15 \%$ for overweight. Various measures of physical work load were considered, but they all proved to be correlated.

Conclusions - Approximately $80 \%$ of the idiopathic coxarthrosis was explained by the presence of the three risk factors.
\end{abstract}

KEY TERMS - case-referent study, dynamic work load, hip, lifting, occupation, osteoarthrosis, prevention, static work load.

Musculoskeletal diseases are among the most important diseases in Western societies today when measured in terms of sick leave, disability pension, or "lost good years of life" (1). The objective of the present study was to estimate the impact of physical work load, sports, and overweight on the incidence of one of these diseases, coxarthrosis.

Similar estimations of occupational etiologic fractions have been carried out previously for the incidence of major and lethal diseases such as cardiovascular diseases (2) and cancer (3-6). However, the epidemiologic quality of the studies published on musculoskeletal diseases has been, in general, not as high (7-9) as for cancer and cardiovascular diseases, and therefore obtaining a reliable estimate is more difficult. Furthermore, the aim of most studies in occupational musculoskeletal epidemiology is to identify occupational risk factors, and rather few studies are left which have examined the population distribution of the risk factors and thus allow a population-based estimation of etiologic fractions.

Department of Occupational Medicine, National Institute of Occupational Health, Denmark.

2 Department of Occupational Medicine, Karolinska Hospital, Stockholm, Sweden.

3 Department of Epidemiology Institute of Environmental Medicine, Karolinska Institute, Stockholm, Sweden.

Reprint requests to: Dr O Olsen, National Institute of Occupational Health, Lers $\varnothing$ Parkallé 105, DK-2100 Copenhagen $\varnothing$, Denmark.
The etiologic fraction (population attributable risk) has been introduced as an appropriate parameter for quantifying the disease-producing role of an etiologic factor, and population-based case-referent studies might directly provide the measures required $(2,10,11)$.

\section{Subjects and methods}

From a case-referent study (12-14) of first-time prosthesis of the hip at four large hospitals in Stockholm, Sweden, the quantitative importance of physical work load, sports, and overweight to the development of coxarthrosis has been studied. The etiologic fraction was calculated with the use of the following operational entities for "physical work load": cumulative number of hours exposed to dynamic work loads, cumulative number of hours working in a twisted locked position, cumulative number of tons lifted, total number of heavy lifts, and cumulative number of jumps. The cumulative numbers were collected up to the age of 49 years, as were the numbers of hours spent in sports activities.

The study base comprised all Swedish men who were between the ages of 50 and 70 years and lived in the referral areas of four large hospitals in Stockholm. Information was collected from 1984 to 1988. The cases were the men in the study population who received a first-time prosthesis of the hip joint as a result of idiopathic osteoarthrosis. The referents were randomly selected from the study base. The main as- 
pects of the design, material, and methods of the study have been presented elsewhere (12-14).

All information about the participants' health status, smoking habits, education, sports activities, and occupational career was obtained in a telephone interview. According to this information, each subject's occupational career was divided into different periods with similar work tasks. For each such period the study participants were asked to complete a questionnaire about the specific physical work loads in that type of work. The subjects were asked how many hours per week were spent in different work positions, how many kilograms were lifted per week, and other such questions. Information regarding exposure was collected from the start of the occupational career to the year of the diagnosis for the cases and to the year of the interview for the referents. Exposure was then aggregated for the men's worklife up to 49 years of age. Three exposure groups were defined according to the loads in the reference group. Those unexposed and the $5 \%$ least exposed were considered to have low exposure. The rest of the exposed men were divided into two equally large groups, classified as the medium-exposed and the high-exposed group.

The etiologic fractions were calculated as follows for the work loads: static + dynamic work, lifted tons, number of lifted heavy burdens ( $>40 \mathrm{~kg}$ ), and number of jumps. The etiologic fraction for sports activities was calculated in the same way as for exposure from work load. The exposure from sports activities was quantified as low, medium, and high according to the total amount of hours spent in sports. The etiologic fractions for overweight were calculated so that the lean group (BMI< mean BMI-1 SD) was considered unexposed and the rest were considered exposed, with the use of unadjusted odds ratios, or so that the lean group was considered the reference group and only those at least slightly obese (BMI> mean BMI+1 SD) were considered exposed, with the use of adjusted odds ratios.

The etiologic fractions were estimated according to principles outlined by Miettinen (11). The etiologic fraction for all the cases in the study population $\left(\mathrm{EF}_{\mathrm{p}}\right.$ ) was calculated as $\Sigma \mathrm{EF}_{\mathrm{e}} \times \mathrm{CF}$, where $\mathrm{CF}$ is the fraction of cases (fraction of all cases) in each category of the determinant and $\mathrm{EF}_{\mathrm{e}}$ is the etiologic fraction for the exposed. $\mathrm{EF}_{\mathrm{e}}$ was calculated as $(R R-1) / R R$, where $R R$ is the adjusted odds ratio for those exposed in each exposure category in comparison with those with the lowest exposure. The adjusted odds ratios were obtained from stratified Mantel-Haenszel analyses (12-14). The $95 \%$ confidence intervals for the $\mathrm{EF}$ were based upon the standard error given by Walter (15). Where indicated, overall etiologic fractions for two or more factors were calculated by means of Miettinen's formula (11):

$$
E F(\text { total })=1-[1-E F(1)] \times[1-E F(2)] \times \ldots[1-E F(n)] .
$$

\section{Results}

The etiologic fractions due to occupational exposures are presented in table 1 for each of four operationalizations of work load. Analyses of cumulative work load up to 29 years of age instead of up to 49 years did not change the etiologic fractions by more than $7 \%$. The various work loads were highly correlated; only 3 of the 31 cases with low exposure to static and dynamic forces had experienced exposure to any of the other loads. An analysis with a reference group comprised of those who had experienced no exposure to any of the variables listed in table 1 yielded an etiologic fraction of $40 \%$. All of these estimates were adjusted for age, body mass index, smoking habits, and sports activities (12).

The etiologic fraction due to sports activities up to 49 years of age was estimated to be $55 \%$ (table 2). The overall etiologic fraction due to occupation and sport can be estimated from tables 7 and 8 in reference 13. With the use of the subjects unexposed to both sports activities and occupational loads as the reference category (only 14 cases), the combined etiologic fraction for occupation or sport or both was estimated to be $66 \%$. However, in table 7 of reference 13, the numbers of hours of sports activities were cumulated only up to 29 years of age. If sports activities are, instead, cumulated up to 49 years of age, the number of unexposed persons becomes smaller, and the relative risks become larger (13). If this larger etiologic fraction for sports activities $(55 \%)$ is combined with the etiologic fraction for occupation (40\%) according to Miettinen's formula, the combined etiologic fraction for occupation and sport is estimated to be $73 \%$.

The etiologic fractions due to overweight are presented in table 3 . They range from 13 to $17 \%$ depending on the choice of reference group and the choice of age at which the body mass index was estimated. With the use of the subjects unexposed to both sports activities (up to 49 years of age) and overweight (at 30 years of age) as the reference category (only 7 cases), the combined etiologic fraction for overweight and sport was estimated to be $82 \%$. If sports activities up to only 29 years of age were used instead, the estimation would be based on 11 cases and the etiologic fraction would be estimated to be $66 \%$.

The combined estimates were subject, however, to large sampling errors based as they were on very few unexposed cases. If the etiologic fractions for occupation (40\%), sports activities (55\%), and overweight (15\%) are combined according to Miettinen's formula, the total etiologic fraction for these exposures is $77 \%$.

\section{Discussion}

To estimate the fraction of disease that can be avoided by reducing or eliminating the population expo- 
Table 1. Etiologic fraction (EF) estimates for various types of physical work loads.

\begin{tabular}{|c|c|c|c|c|}
\hline Type of work load & $\begin{array}{l}\text { Number } \\
\text { of cases }\end{array}$ & $\begin{array}{l}\text { Risk } \\
\text { ratio }\end{array}$ & $\begin{array}{l}\text { EF for } \\
\text { exposed } \\
\left(E_{e}\right)\end{array}$ & $\begin{array}{c}\text { EF for } \\
\text { all cases } \\
\left(E F_{p}\right)\end{array}$ \\
\hline \multicolumn{5}{|l|}{ Static + dynamic work } \\
\hline $\begin{array}{l}\text { Low exposure } \\
\text { Medium exposure } \\
\text { High exposure } \\
\text { Medium + high exposure } \\
95 \% \text { confidence interval }\end{array}$ & $\begin{array}{r}31 \\
68 \\
94 \\
162 \\
.\end{array}$ & $\begin{array}{l}1 \\
1.82 \\
2.42 \\
:\end{array}$ & $\begin{array}{l}0.45 \\
0.59 \\
:\end{array}$ & $\begin{array}{c}0.16 \\
0.29 \\
0.44 \\
0.24-0.64\end{array}$ \\
\hline \multicolumn{5}{|l|}{ Tons lifted } \\
\hline $\begin{array}{l}\text { Low exposure } \\
\text { Medium exposure } \\
\text { High exposure } \\
\text { Medium + high exposure } \\
95 \% \text { confidence interval }\end{array}$ & $\begin{array}{r}44 \\
66 \\
83 \\
149\end{array}$ & $\begin{array}{l}1 \\
1.58 \\
1.84 \\
\cdot \\
\cdot\end{array}$ & $\begin{array}{l}0.37 \\
0.46 \\
:\end{array}$ & $\begin{array}{c}0.13 \\
0.20 \\
0.32 \\
0.11-0.53\end{array}$ \\
\hline \multicolumn{5}{|l|}{ Number of lifts (>40 kg) } \\
\hline $\begin{array}{l}\text { Low exposure } \\
\text { Medium exposure } \\
\text { High exposure } \\
\text { Medium }+ \text { high } \\
95 \% \text { confidence interval }\end{array}$ & $\begin{array}{r}87 \\
41 \\
65 \\
106 \\
\end{array}$ & $\begin{array}{l}1 \\
1.38 \\
2.48 \\
:\end{array}$ & $\begin{array}{l}0.28 \\
0.60 \\
:\end{array}$ & $\begin{array}{c}0.06 \\
0.20 \\
0.26 \\
0.13-0.39\end{array}$ \\
\hline \multicolumn{5}{|l|}{ Number of jumps } \\
\hline $\begin{array}{l}\text { Low exposure } \\
\text { Medium exposure } \\
\text { High exposure } \\
\text { Medium + high exposure } \\
95 \% \text { confidence interval }\end{array}$ & $\begin{array}{r}103 \\
44 \\
46 \\
90\end{array}$ & $\begin{array}{l}1 \\
1.83 \\
1.52 \\
:\end{array}$ & $\begin{array}{l}0.45 \\
0.34 \\
\cdot\end{array}$ & $\begin{array}{c}0.10 \\
0.08 \\
0.18 \\
0.05-0.31\end{array}$ \\
\hline
\end{tabular}

a Adjusted for age, body mass index, smoking, and sports activities. From table 5 in reference 12.

Table 2. Etiologic fraction (EF) estimates for sports activities.

\begin{tabular}{lcccc}
\hline & $\begin{array}{c}\text { Number } \\
\text { of cases }\end{array}$ & $\begin{array}{c}\text { Risk } \\
\text { ratio }\end{array}$ & $\begin{array}{c}\text { EF for } \\
\text { exposed } \\
\left(E_{\mathrm{e}}\right)\end{array}$ & $\begin{array}{c}\mathrm{EF} \text { for } \\
\text { all cases } \\
\left(\mathrm{EF}_{\mathrm{p}}\right)\end{array}$ \\
\cline { 2 - 5 } Sports activities & & & & \\
$\quad$ Low exposure & 44 & 1 & 0.62 & 0.18 \\
Medium exposure & 55 & 2.6 & 0.78 & 0.38 \\
High exposure & 94 & $\cdot .5$ & $\cdot$ & 0.55 \\
Medium + high exposure & 149 & $\cdot$ & $\cdot$ & $0.40-0.70$ \\
95\% confidence interval & $\cdot$ & $\cdot$ & \\
\hline
\end{tabular}

a Adjusted for age, body mass index, smoking, and physical loads from occupation. From table 4 in reference 13.

sure to a given etiologic agent is a prerequisite for evaluating disease-preventing strategies. However, estimates of etiologic fractions must be interpreted with caution, as they presuppose that the observed relations between factors and disease are causal relationships, and not merely statistical associations. The associations studied in this paper fulfill most of Bradford Hill's relevant criteria $(16,17)$ for causality, namely, strength of the association (relative risks above 2, except for overweight), dose-response effect present except for the small group with extreme overweight, lack of temporal ambiguity, the hypothesis about "wear and tear" (common for all three of the studied risk factors) biologically plausible, supportive experiments on animals available (12), consistency of the findings [the association between coxarthrosis and occupational load being repeated in a large, long-term, prospective register study (18), the association between coxarthrosis and sports activi- ties being repeated in the two best of three studies on top athletes (13), but the quality of studies on overweight being generally of lower quality and giving inconsistent results].

The sources of bias, misclassification, and confounding in the present study have been discussed earlier (12-14), and they are generally expected to be of minor importance. As far as the given estimates represent causal relationships, they contribute to the discussion on the proportions of coxarthrosis which might be due to physical work load, sports, and overweight and which thereby could theoretically have been prevented.

As "occupational exposure" is an inaccurate description of exposure to a multitude of specific physical work loads during a work career, the estimates of the fraction of a disease due to "occupational exposure" are highly dependent upon the definition and categorization of the exposure variable. Etiologic 
Table 3. Etiologic fraction (EF) estimates for overweight. ( $\mathrm{BMI}=$ body mass index)

\begin{tabular}{|c|c|c|c|c|}
\hline BMI & $\begin{array}{l}\text { Number } \\
\text { of cases }\end{array}$ & $\begin{array}{c}\text { Risk } \\
\text { ratio }\end{array}$ & $\begin{array}{l}\text { EF for } \\
\text { exposed } \\
\left(E F_{e}\right)\end{array}$ & $\begin{array}{l}\text { EF for } \\
\text { all cases } \\
\left(\mathrm{EF}_{\mathrm{p}}\right)\end{array}$ \\
\hline \multicolumn{5}{|l|}{30 years of age } \\
\hline $\begin{array}{l}\text { Lean (BMI<mean } \mathrm{BMI}-1 \mathrm{SD}) \\
\text { Normal (mean } \mathrm{BMI}-1 \mathrm{SD} \leq \mathrm{BMI} \leq \text { mean } \mathrm{BMI}+1 \mathrm{SD}) \\
\text { Slightly overweight (mean } \mathrm{BMI}+1 \mathrm{SD}<\mathrm{BMI}<\text { mean } \mathrm{BMI}+2 \mathrm{SD}) \\
\text { Severely overweight (BMI } \\
\text { Information unavailable }\end{array}$ & $\begin{array}{r}31 \\
116 \\
48 \\
27 \\
17 \\
222\end{array}$ & $\begin{array}{l}1.04 \\
1.69 \\
1.28 \\
0.83\end{array}$ & $\begin{array}{l}0.03 \\
0.41 \\
0.22\end{array}$ & $\begin{array}{l}0.02 \\
0.09 \\
0.03 \\
0.13\end{array}$ \\
\hline $\begin{array}{l}\text { The slightly and severely overweight as a fraction } \\
\text { of the population } \\
95 \% \text { confidence interval }\end{array}$ & 0.34 & $1.81^{\mathrm{c}}$ & . & $\begin{array}{c}0.15 \\
0.05-0.25\end{array}$ \\
\hline \multicolumn{5}{|l|}{40 years of age } \\
\hline $\begin{array}{l}\text { Lean (BMI<mean } B M I-1 \text { SD) } \\
\text { Normal (mean BMI }-1 \text { SD } \leq B M I \leq \text { mean } B M I+1 \text { SD) } \\
\text { Slightly overweight (mean } \mathrm{BMI}+1 \text { SD }<\mathrm{BMI}<\text { mean } \mathrm{BMI}+2 \mathrm{SD} \text { ) } \\
\text { Severely overweight (BMI } \geq \text { mean } \mathrm{BMI}+2 \mathrm{SD} \text { ) } \\
\text { Information unavailable }\end{array}$ & $\begin{array}{r}35 \\
124 \\
43 \\
17 \\
20 \\
219\end{array}$ & $\begin{array}{l}1.11 \\
1.79 \\
1.67 \\
1.02\end{array}$ & $\begin{array}{l}0.1 \\
0.44 \\
0.4\end{array}$ & $\begin{array}{l}0.06 \\
0.09 \\
0.03 \\
0.17\end{array}$ \\
\hline $\begin{array}{l}\text { The slightly and severely overweight as a fraction } \\
\text { of the population } \\
95 \% \text { confidence interval }\end{array}$ & 0.27 & $2.49^{c}$ & . & $\begin{array}{c}0.16 \\
0.07-0.25\end{array}$ \\
\hline
\end{tabular}

fractions for four different measures of physical work load were presented. These measures were, however, so closely correlated that it was impossible to distinguish the specific effects of the various risk factors. Thus the data simply indicated that approximately $40 \%$ of the coxarthroses might have been prevented if all occupational work loads had been eliminated.

With regard to the external validity of the occupational etiologic fraction, the Greater Stockholm area, in which the study was performed, is somewhat more urbanized than the average for the country. However, one of the hospitals in the study covered a rural region, and, due to migration and urbanization in the 1950s and 1960s, the study base probably comprised a sample of work careers that was fairly representative for Sweden. The estimate, however, is historical, as it was based on, and primarily appropriate for, the generations who worked in the middle of this century. If society had been in steady state, it would cause no problem to apply the obtained estimate to future generations as well. But some of the physical work loads that were previously common or at high levels are now, to a large extent, controlled (at least in our part of the world). Thus it can be expected that the occupational etiologic fraction will decrease in the future. However, due to similar occupational structures and similar changes in it, the estimate is probably applicable to middle-aged and elderly generations in other Nordic countries.

Calculations similar to the ones made in the present paper have been performed in only one oth- er study, a Finnish study based on a representative sample of the population aged 30 years or over and including both men and women (19). In that study the total etiologic fraction for prior trauma of the lower limbs, physical stress at work, and overweight was 59\% (note that sports were not included). The etiologic fractions for physical stress at work and overweight can be calculated with the aid of table 2 in reference 19 , and the etiologic fractions are 37 and $24 \%$, respectively. The former is very close to the $40 \%$ calculated in the present paper, and the $24 \%$ for overweight is within the confidence limits of the estimate for overweight presented in the present paper.

No other studies allow similar calculations of an etiologic fraction for coxarthrosis. However, using a case-referent study of disability pension due to musculoskeletal disorders (20), we were able (with the aid of table 4 in the paper) to calculate an occupational etiologic fraction from the occupational titles for the hip cases $\left(\mathrm{EF}_{\mathrm{p}}=72 \%\right)$, knee cases $\left(\mathrm{EF}_{\mathrm{p}}=75 \%\right)$, neck and shoulder cases $\left(\mathrm{EF}_{\mathrm{p}}=69 \%\right)$, and low-back cases $\left(\mathrm{EF}_{\mathrm{p}}=71 \%\right)$. These etiologic fractions should, however, be interpreted with great caution, as they may reflect both a causal relationship and the difficulty in continuing work in certain occupations while suffering from a musculoskeletal disorder. In the cross-sectional HANES I study (21), an occupational etiologic fraction of radiographic osteoarthritis of the knee was estimated to be $32 \%$. Unfortunately the studies of neck and shoulder disorders (7-9) and of low-back pain (22, p 28) are generally of low epidemiologic quality and do not 
permit etiologic fractions to be estimated. The few good studies, however, provide large odds ratios and suggest that the etiologic fractions may be appreciable.

The etiologic fraction for sports activities of all kinds was $56 \%$. The most hazardous sports seemed to be track and field, racket sports, and soccer (13). However, the participants in individual sports were few, and the results must be interpreted with caution on this level. The estimate of the etiologic fraction for sports activities in general was, however, so large that it warrants further research into the different loads and possible later deleterious effects of various sports. This finding is important, especially in light of the many positive aspects of sports activities in general.

It should be pointed out that the individual etiologic fractions of two factors contributing to a multifactorial disease are not invalidated, although their sum exceeds $100 \%$, and each estimate must be interpreted as a measure of disease reduction if the factor in question was the first to be eliminated (22). It is furthermore possible to calculate etiologic fractions for preventive strategies covering the simultaneous elimination of several factors (23). The present study indicates that approximately half of the occurrences of coxarthrosis in the present generation might have been prevented by the elimination of either of the single factors occupational exposure or sports activities. Approximately $75 \%$ of the occurrences might have been prevented if physical work load, sports, and overweight had all been eliminated.

Although, clinically, idiopathic coxarthrosis has been considered a disease "occurring without known cause" (24), we conclude that the occurrence of the disease, from an epidemiologic point of view, turns out to be highly explainable, understandable, and preventable.

\section{Acknowledgments}

This work was funded by the Nordic Council of Ministers.

The authors thank Ms L Vindelbo for correcting the language, and the authors thank a referee for bringing reference 19 to our attention.

\section{References}

1. Bredkjær SR. Rygbesvær og andre lidelser $\mathrm{i}$ bevægeapparatet hos danskerne [Back problems and other musculoskeletal disorders in the Danes]. Copenhagen: Dansk Institut for Klinisk Epidemiologi, 1989.

2. Olsen O, Kristensen TS. Impact of work environment on cardiovascular diseases in Denmark. J Epidemiol Community Health 1991;45:4-10.

3. Vineis P, Simonato L. Estimates of the proportion of bladder cancers attributable to occupation. Scand J Work Environ Health 1986;12: 55-60.

4. Vineis P, Thomas T, Hayes RB, Blot WJ, Mason TJ,
Pickle LW, et al. Proportion of lung cancers in males, due to occupation, in different areas of the USA. Int J Cancer 1988;42:851 -6.

5. Vineis $\mathrm{P}$, Simonato L. Proportion of lung and bladder cancers in males resulting from occupation: a systematic approach. Arch Environ Health 1991;46:6-15.

6. Simonato L, Vineis P, Fletcher AC. Estimates of the proportion of lung cancer attributable to occupational exposure. Carcinogenesis 1988;9:1159-65.

7. Hagberg M, Wegman D. Prevalence rates and odds ratios of shoulder-neck diseases in different occupational groups. Br J Ind Med 1987;44:602-10.

8. Stock SR. Workplace ergonomic factors and the development of musculoskeletal disorders of the neck and upper limbs: a meta-analysis. Am J Ind Med 1991;19:87-107.

9. Gerr F, Letz R, Landrigan JP. Upper-extremity musculoskeletal disorders of occupational origin. Annu Rev Public Health 1991;12:543-66.

10. Levin ML. The occurrence of lung cancer in man. Acta Unio Int Contra Cancrum 1953;9:531-41.

11. Miettinen OS. Proportion of disease caused or prevented by a given exposure, trait or intervention. Am $\mathbf{J}$ Epidemiol 1974;99:325-32.

12. Vingård $\mathrm{E}$, Hogstedt $\mathrm{C}$, Alfredsson L, Fellenius $\mathrm{E}$, Goldie I, Köster M. Coxarthrosis and physical work load. Scand J Work Environ Health 1991;17:104—9.

13. Vingård E, Alfredsson L, Goldie I, Hogstedt C. Sports and osteoarthrosis of the hip - an epidemiologic study. Am J Sports Med 1993;21(2):195-200.

14. Vingård E. Overweight predisposes to coxarthrosis body-mass index studied in 239 males with hip anthroplasty. Acta Orthop Scand 1991;62:106-9.

15. Walter SD. Calculation of attributable risks from epidemiological data. Int J Epidemiol 1978;7:175-82.

16. Kleinbaum DG, Kupper LL, Morgenstern H. Epidemiologic research - principles and quantitative methods. New York, NY: Van Nostrand Reinhold Company Inc, 1982.

17. Rothman KJ. Modern epidemiology. Boston, MA: Little, Brown, 1986.

18. Vingård E, Alfredsson L, Goldie I, Hogstedt C. Occupation and osteoarthrosis of the hip and knee: a register-based cohort study. Int J Epidemiol 1991;20: $1025-31$.

19. Heliövaara M, Mäkelä M, Impivaara O, Knekt $P$, Aromaa A, Sievers K. Association of overweight, trauma and workload with coxarthrosis - a health survey of 7217 persons. Acta Orthop Scand 1993;64(5):513-8.

20. Vingård $\mathrm{E}$, Alfredsson L, Fellenius E, Hogstedt C. Disability pensions due to musculo-skeletal disorders among men in heavy occupations - a case-control study. Scand J Soc Med 1992;20:31-36.

21. Anderson JJ, Felson DT. Factors associated with osteoarthrosis of the knee in the first national health and nutrition examination survey (HANES I) - evidence for an association with overweight, race, and physical demands of work. Am J Epidemiol 1988;128:179_89.

22. Kilbom Å, Hagberg M. Arbetsrelaterade muskuloskeletala sjukdomar - riskyrken och riskfaktorer [Work related musculoskeletal diseases-risk occupations and risk factors]. Stockholm: Arbetsmiljöinstitut, 1990.

23. Olsen O, Kristensen TS. Hvor stor betydning har arbejdsmiljøet for hjertekarsygdomme i Danmark? [How large is the impact of the work environment on cardiovascular diseases in Denmark?].København: Arbejdsmiljøfondet, 1988.

24. Idiopathic. Dorland's pocket medical dictionary. 24th ed. Philadelphia, PA: Saunders, 1989.

Received for publication: 11 October 1993 